\section{Monitoreo de}

\section{parámetros}

\section{físico-químicos,}

en la cuenca

alta del río

Bogotá

Revista Ciencial L hagenieria Neogramadias ISSN 0124-8170 No. 12 - jullio de 2002

(Págs. 23-30)
JULIA Sierra', AlexandRA JaIME ${ }^{2}$

ANDREa MORA ${ }^{2}$

\title{
RESUMEN
}

T a Universidad Milicar "Nueva Granada" en L su constante interés por el clesarrollo de nuevas técnicas que permitan la preservación del medio ambiente, inició en el año 2000 la investigación "IDENTIFICACIÓN Y PRUEBA DE BIOINDICADORES Y RECUPERADORES PARA LA DESCONTAMINACIÓN DEL RIO BOGOTÁ". En la primeral fase de este estudio se hace un diagnóstico de la situación actual de la cuenca alta del Río Bogotá, a través de los proyectos de grado presentados por los estudiantes de la Universidad y dirigidos por un grupo de profesores.

Se realizó una investigación como Tesis de Grado para optar al tículo de Ingeniero Civil, donde se analiza el comportamiento de los parấmetros físico-cuímicos en la cuenca alta del Río Bogotai estos parámetros son de gran importancia ya que establecen las modificaciones que sufre una corriente superficial, como consecuencia de los diferentes usos del agua (causados por

Ingeniera quimica, docente de Biología Aplicada e Ingeniería Civil. Universidad Militar Nueva Granada, jsierra@cordova.nmng.edu.co

2 Estudiantes de Ingenieria Civil áltimo semestre. Universidad Militar Nueva Granadio. 
activiclades industriales, doméscicas, recreativas y de transporte).

El título del trabajo de grado es "MONITOREO DE PARÁMETROS FISICO-QUIMICOS, EN LA CUENCA ALTA DEL RÍO BOGOTÁ". Los aspectos físicos que se tienen en cuenta en este trabajo son: turbiedad, temperatura y conductividad, y como aspectos químicos oxígeno disuelto, demanda bioquímica de oxígeno (DBO), demanda química de oxigeno (DQO), pH, alcalinidad total, acidez, dureza, cloruros, amonio, nitritos, nitratos, fosfatos altos y bajos, sulfaros, cromo, cobre y cloro total.

Palabras clave: Contaminación Río Bogotá, moniroreo "in siru", parámetros flsico-químicos. descargas domésticas e industriales.

\section{SUMMARY}

A rescarch named "IDENTIFICATION AND TEST OF BIO-INDICATORS AND RECUPERATORS FOR DESCONTAMINATION OF BOGOTA RIVER" has been scarted in the Nueva Granada Military University on the year 2000 , in order to develop some new technologies that help the preservation of environment.

The first part of this research is related to diagnostic of current situation in the higher basin of the river, through graduation projects of students, under direction of a professor's team of our Engineering School.

Specifically this graduation work, was made as a condition to obtain the title of Civil Engineers, and analyses the behaviour of pliysical and chemical parameters in the catchment's area of the Bogota River, as fundamental indicarors of the modifications that the river current suffers as consequence of different usages of water (industrial, domestic, leisure or transport activities). Physical aspects considered, were: turbidity, temperature and conducrivity; chemical aspects, as: dissolved oxygen, biochemical demand of oxygen (DBO) chemical demand of oxygen (DQO), $\mathrm{pH}$, total al kalinity, acidity, hardness, chlorides, ammonium nitrites, nitrates, high and low phosphates, sul phates, chromo, cupper, total chlorares.

Key Words: Bogotá river contamination, "ir situ" monitoring, physique-chenical parameters industrial and domestic discharges.

\section{INTRODUCCIÓN}

En mayo de 2000 se inició el monitoreo y análisis de muestras de agua tomadas en la cuen. ca alta del Río Bogotá, analizánclose en principio algunos paránetros, a los cuales después se fueron adicionando otros, hasta completar los 23 parámetros que se estudiaron con el fin de hacer un diagnostico de la situación actual del río. Este trabajo corresponde al Proyecto de Grado de las alumnas Alexandra Jaime y Andrea Mora, dirigidos por la Ing. Julia Sierra Plazas.

\section{MATERIALES Y MÉTODOS}

El análisis de las muestras se realizo en canpo y ell laboratorio, empleando en campo algunos instrumentos como el fotometro (para medir las concentraciones de alcalinidad, amonio, nitratos, nitritos, cobre, sulfatos, cromo VI, fosfatos altos y bajos, y cloro) y el medidor de oxígeno disuelto. En los análisis que se llevaron a cabo en la universidad, se emplearon el potenciómecro o medidor de $\mathrm{pH}$, conductivímetro, citulador automático y urrbidímetro.

El método, en general, comprende tres etapas que son monitoreo "in situ", dos veces al mes y en algunas ocasiones cada ocho días, procesamienco en el laboratorio y análisis de resultados.

El trabajo de campo se llevó a cabo en tres estaciones ubicadas en la Cuenca Alta del Río Bogotá que se denominan E-1 localizadas aguas arri- 
ba del municipio de Villapinzón, la Estación E-2 localizada 8 kilómetros aguas abajo de la cabecera municipal y finalmente la E-3 que se encuentra ubicada en las inscalaciones de la Hacienda Ríogrande, de propiedad de la Universidad Militar Nueva Granada, sobre la vía Canjicá-Bogotá.

En estos puntos estratégicos se recolectan muestras de agua y se analizan algunos parámetros como oxigeno clisuelto, temperatura, conductividid, $\mathrm{pH}$, turbiedad, alcalinidad, nitratos, nitritos, amonio, colsre, sulfatos, cromo, fosfaros altos y bajos y cloro libre.

Los parámetros restantes se analizan en el Laboratorio de Aguas de la UMNG; en esta fase es imporrante la conservación de muestras.

A continuación se hace un estudio del comportamiento de cada parámetro para cacla estación y así poder obtener un diagnóstico del río. que es el objetivo fundamental del trabajo de grado.

En este artículo sólo se tienen en cuenta algunos parámetros químicos. El estudio completo se encuentra en el trabajo de grado Monitoreo de Parámetros Físicos-Químicos, Cuenca Alta del Río Bogotí.

\section{ANÁLISIS DE RESULTADOS}

Después de recolectar la información necesaria y analizarla, se pueden señalar algunos parámetros que indican la situación del río Bogotá en cada una de las estaciones. El oxígeno disuelro es importance ya que indica su cancidad presente en la corriente; esta concentración ayuda al río a degradar la materia orgánica que llega a su cauce y disminuye el impacto causado por los vertimientos de los alcantarillados municipales y los residuos industriales.

Como se puede observar en la figural. en la primera estación la concentración de oxígeno disuelto es alta, siendo un factor importance la movilización del río que colabora con la mayor oxigenación del cauce. En la segunda estación (después de Villapinzón). la disminución de oxígeno disuelto es grande como consecuencial de los vertimientos incontrolados de Villapinzón y de las curtiembres situadlis en la zona, que afecta considerablemente la concentración de oxigeno disuelto. La estación 3 presenta una situación similal al la estación dos. donde el oxígeno clisuelto presenta valores muy bajos.

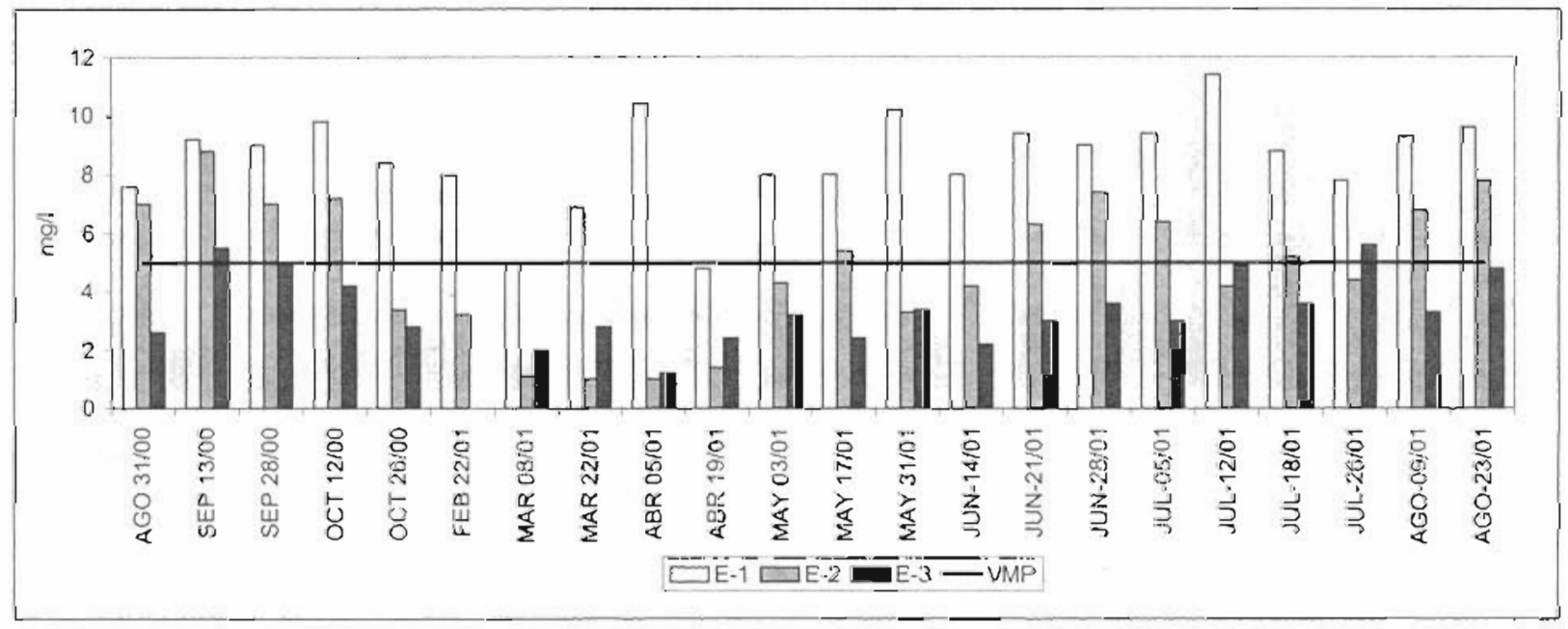

Figura I. Variación en la concentración de oxígeno disuelto en el periodo del 31 de agasta de 2000 al 23 de agosto de 2001 
Durante los meses de marzo y abril de 2001 , debido a las sequias que se presentaron en las zonas donde se encuentran ubicadas la segunda y tercera estación, disminuyó el valor de oxígeno clisuelto, yal que la deficiencia de este elemento ocurre con mayor frecuencia en los meses de verano clando disminuye el caudal y el ascenso de temperacura incrementa las velocidades de oxidación, aumentando así la demanda de oxígeno y haciéndolo menos soluble en el agua. De igual manera, al no haber mayor grado de dilución, hay mayor concencración de contaminantes, lo cual trae como consecuencia la disminución en la capacidad de purificación del río.

Para este período de monitoreo, la variación de la concentración de oxígeno disuelto en la primeral estación se encuentra entre 4.8 y 11.4 ingil de $\mathrm{O}_{2}$, en la segunda estación entre 1.0 y $8.8 \mathrm{mg} /$ de $\mathrm{O}_{2}$ y la tercera esta entre 1.2 y $5.6 \mathrm{mg} / \mathrm{de} \mathrm{O}_{2}$.

La $\mathrm{DBO}_{5}$ indica la cancidad de oxígeno que necesitan las bacterias para estabilizar la materia orgánica degradable bajo condiciones aeróbicas. Este parametro se emplea principalmente para cuancificar el grado de polución de una corriente de agua.
Los registros obtenidos en los meses de marzo y abril no deben tenerse en cuenta, ya que en este periodo se estaba estandarizando el mécodo.

De acuerdo con la figura 2, primera y cercera estación, es de notable consideración la estabilidad que presenta este parámetro, deduciendo asi un bajo grado de contaninación, lo que significa que las condiciones para descomponer la materia orgúnica por medios aeróbicos son muy buenas. Por el contrario, para la segunda estación, los valores son mayores y más inestables que los de las estaciones inencionadas anteriormente, debido al grado de contaminación en esta estación, por las curtiembres presentes en el sector Chocontá - Villapinzón.

El 12 de julio de 2001, la estación 1 presenta la mayor carga de materia orgánica con respecto a los valores de las otras dos estaciones en la misma fecha. Esto podría indicar el vertimiento de desechos orgánicos al cuerpo de agua en una época cercana a la toma de la muestra.

Entre junio y julio debió producirse una alta actividad industrial en la cual los vertimientos de

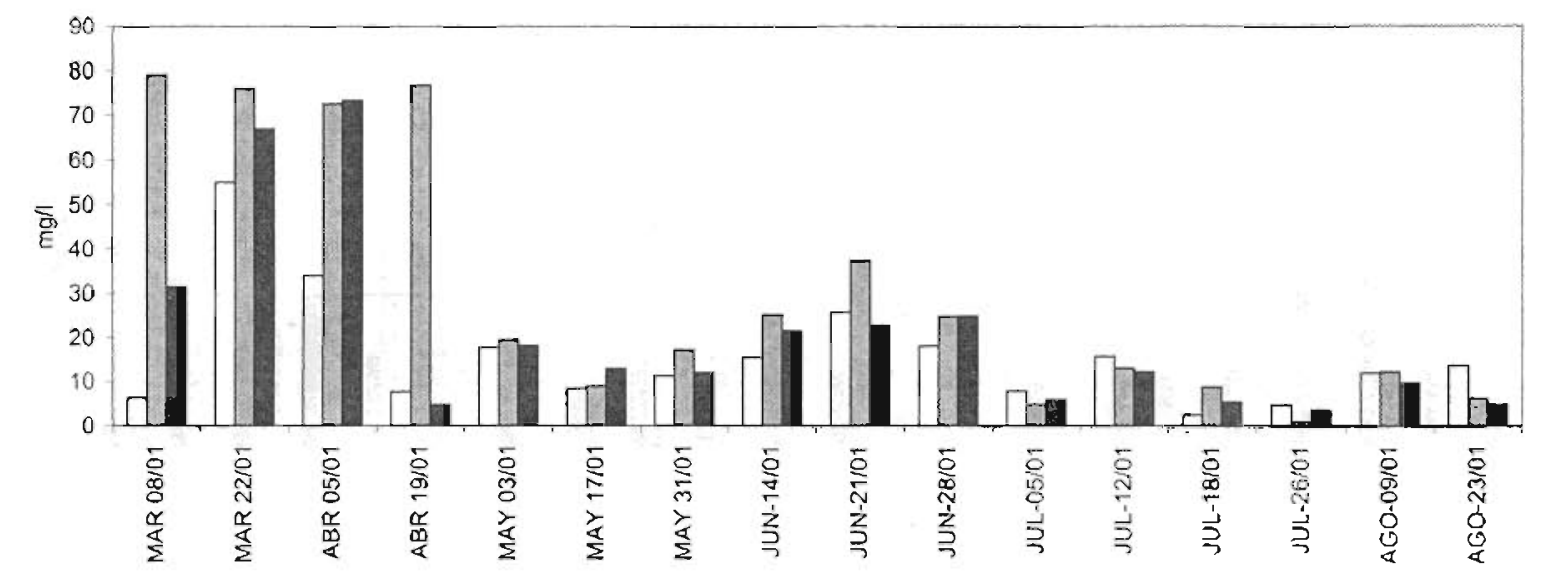

$\square E-1 \square E-2 \square E-3$

Figura 2. Variación de la demanda bioquímica de oxígeno $\left(\mathrm{DBO}_{5}\right)$ en el periodo comprendido entre el 8 de marzo y el 23 de agosto de 2001 


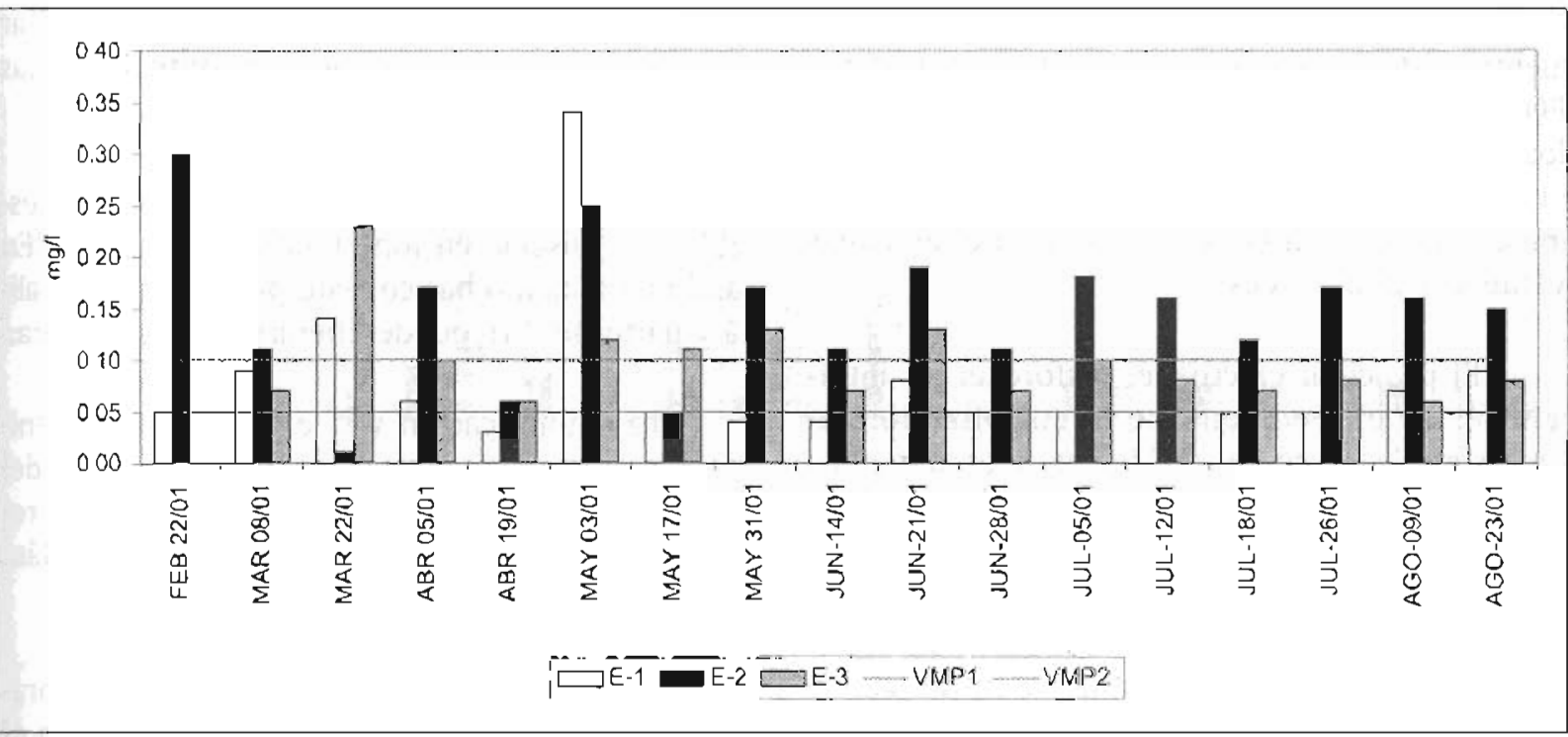

Figura 3. Variación de la concentración de cromo hexavalente en el período comprendido entre el 22 de febrero y el 23 de agosto de 2001.

igua residual industrial aumentaron, variando así los datos en los siguientes meses.

La primera estación presenta un rango de variación encre 2.5 y $25.6 \mathrm{mg} \Lambda$, en la estación dos este rango se sitúa entre 0.9 y $37.4 \mathrm{mg} / \mathrm{l}$ y para la estación tres entre 3.6 y $24.8 \mathrm{mg} /$.

El cromo puede presentarse de diversas formas de acuerdo con su valencia, así el cromo trivalente es una forma útil nutricionalmente. mientras que el hexavalente puede producir enfermedades de piel, hepáticas y hasta se ha llegado a pensar que es cancerígeno.

Ahora se analiza el cromo hexavalente $(C r+6)$ el cual llega al cauce del río Bogotá por diversas causas al ser utilizado en la fabricación de fertilizantes, colorances, detergenres y plaguicidas, por lo general diluidos en agua que después de ser empleados llegan al cauce del río por escorrentía o por la descarga de los alcantarillados.

Sin embargo, la principal fuente de contaminación por cromo hexavalente en el río Bogotá es la utilización de este elemento en el proceso de curtido. ya que de las 111 curtiembres ubicadas en el sector Villapinzón - Chocontá, 80 utilizan el curtido al cromo como proceso de producción de cueros, representando así 72\% de las industrias dedicadas a esta actividad en la zona; como se observa en la figura 3, la segunda estación es la que presenta las mayores concentraciones de este elemento.

En la estación uno, los datos son relativamente constantes, es decir no se observan variaciones drásticas en los valores a lo largo del año. En general el intervalo es de 0.03 a $0.14 \mathrm{mg} / \mathrm{lde}$ cromo.

La tercera estación inuestra una disminución en la concentración de cromo y su rango de variación es de 0.06 á $0.23 \mathrm{mg} /$.

Dad́o que los fosfatos y los compuestos de] nitrógeno son indispensables para el crecimiento de algas y cianobacterias, se deben controlar las concentraciones de estos elementos que regulan las tasas de crecimiento de dichos organismos. 
Las formas más frecuentes en las que se encuentra el fósforo en el agua son los ortofosfatos $\left(\mathrm{PO}_{4}{ }^{3}\right)$, polifosfato y fósforo orgánico. Los derivados del fósforo son utilizados como fertilizantes, en las formulaciones de detergentes, etc. Además, aparece como componente normal de las aguas residuales domésticas.

El principal efecto del fósforo es su intervención en el fenómeno de la eutrofización. El ión fosfato $\mathrm{PO}_{4}^{-3}$, en general forma sales muy poco solubles y se precipica fácilmente como fosfato cálcico.

Según la figura 4, la estación uno presenta los menores valores de fosfatos, mientras que la dos y la tres registran valores muy cercanos, excepto en marzo de 2001. donde la estación dos aumenta considerablemente su valor.

El rango de variación en la concentración de fosfacos para la primera estación está comprendido entre 0.7 y $34 \mathrm{mg} / \mathrm{l}$, para la segunda estación entre 7.5 y $77 \mathrm{mg} / \mathrm{l}$ y finalmente, para la estación tres, entre 8.7 y $42 \mathrm{mgl}$.

La amonificación es la formación de amoníaco, a partir de la descomposición de la materia orgánica. Este proceso se realiza por lo regular en el sedimento y en él actúan tanto bacterias aeróbicas como anaeróbicas.

El amoníaco en medio ácido o neutro es inestable y se disocia en ion amonio e hidroxilos. En cambio, en medio básico, este proceso no se realiza y parte del $\mathrm{NH}_{3}$ puede liberarse a la atmósfera.

La amonificación y la excreción de los animales acuáticos constituyen la fuente principal del amoníaco en el agua, aunque la amonificación representa la inayor parce de este proceso. (Roldán, 1992)

En un cuerpo de agua con alta incorporación de materia orgánica, como se observó en el análisis de $\mathrm{DBO}_{5}$, la amonificación bacteriana debe ser la responsable de las altas concentraciones de amonio que se observan en la figura 5 , sobre rodo рara la estación 2 , donde altas $\mathrm{DBO}_{5}$ corresponden a altas concentraciones de amonio. Nótese el comportamiento de ambas graficas para el 19 de abril de 2001 , donde una altísima $\mathrm{DBO}_{5}$ corresponde a una alta cantidad de amonio.

Por lo mencionado anteriormente se puede decir que la presencia de amonio en el río Bogotá

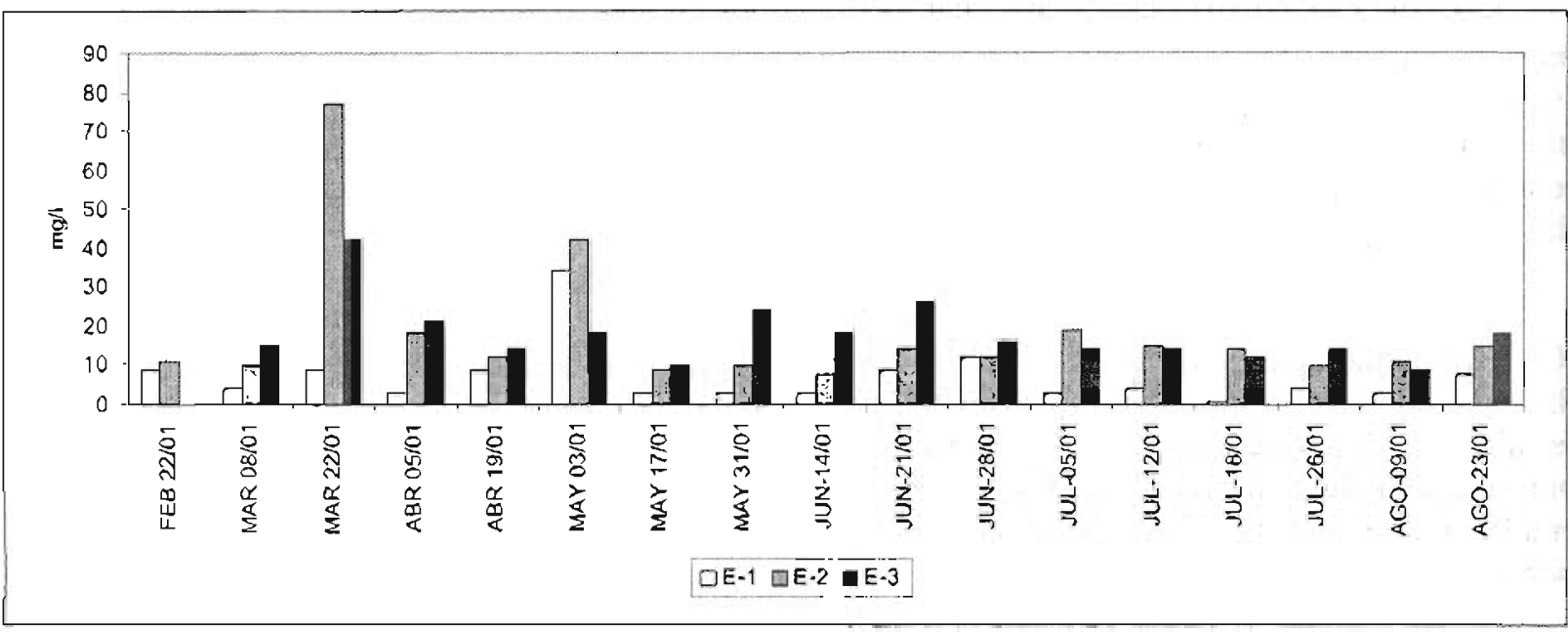

Figura 4. Variación en la concentración de fosfatos en el periodo comprendido entre el 22 de febrero y el 23 de agosto de 2001. 


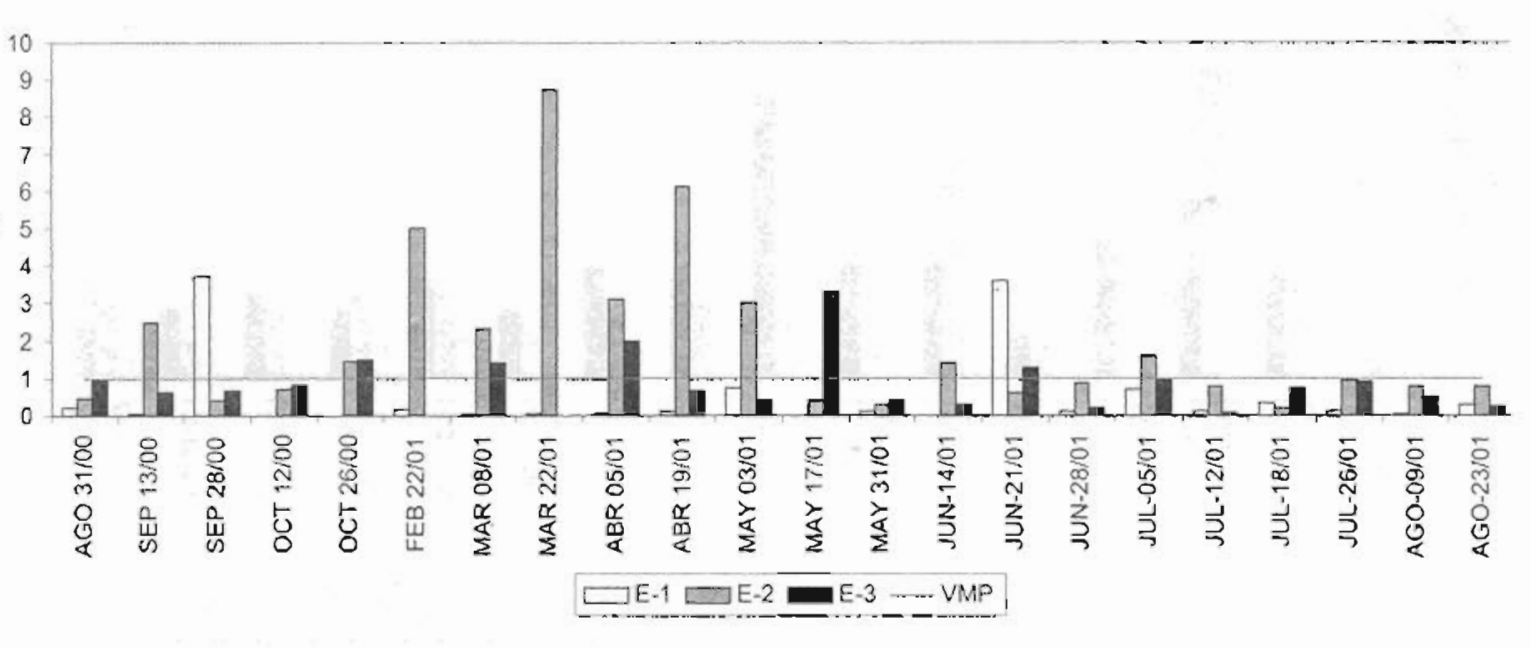

Figura 5. Variocion en la concentración de amonio en el periodo comprendido entre el 31 de agosto de 2000 y el 23 de agosto de 2001.

es atribuída principalmente a las descargas de las aguas residuales agricolas y de los alcantarillados, ya que la excreción líquida conciene el nitrógeno resultante de la degradación de las proteínas y este se comvierte facilmente en carbonato de amonio; de igual inanera, en el sector agrícola la úrea, (que es un compuesto del amonio) es suministrada al suelo con el fin de producir mayor cantidad de proceínas y mejorar así las condiciones de los cultivos.

El rango de variación del amonio para la primera estación se encuentra entre 0 y $3.70 \mathrm{mg} /$, para la segumda entre 0.20 y $8.7 \mathrm{mg} /$ y para la tercera entre 0.01 y $3.30 \mathrm{mg} /$. De acuerdo con los Artículos 38 y 39 del Decreto 1594 de 1984 el valor miximo permisible para collsumo humano y domistico de ritrógeno amoniacal, es de 1 mgl; de los tatos tomados, $26 \%$ no cumplen con la norma.

La segunda estación es la que presenta el whor más ailto en concentración de amonio, debido a los vertimientos de las aguas residuales agricolas, domésticas, de escorrentía e industriales.

Lú fortma inás común de encontrarse el azufre en el agua es como $\mathrm{SO}_{4}{ }^{3}$ (ion sulfato). El ión sulfato $\mathrm{SO}_{4}=$, corresponde a sales entre moderadamente solubles a muy solubles, y llega al agua a través de la lluvia y por disolución de rocas que contengan compuestos, tales como $\mathrm{CaSO}_{4}$ y $\mathrm{FeS}_{2}$ (pirica). La presencia de $\mathrm{H}_{2} \mathrm{~S}, \mathrm{HS}^{-}$y $\mathrm{SO}_{-1}=$ está íntimamente relacionada con el pH del agua. En términos generales, enpH superiores a 8.0, la mayoría del azufre reducido existe en solución como HS y $\mathrm{SO}_{4}=$, en cambio, el $\mathrm{H}_{2} \mathrm{~S}$ se encuentra en pequeñas cantidades y su olor es prácticamenre imperceptible.

En pH inferiores a 8.0, comienza a formarse rảpidamente gran cancidad de H,S alcanzando su máxima concentración en un $\mathrm{pH}^{\circ}$ de 5.0.

El ión sulfaco es uno de los aniones más abundantes en las aguas naturales y su presencia es necesaria para poder llevar a cabo la síntesis de proteínas.

Como se observa en lá figura 6. el contenido de sulfatos se va incrementando a medida que se avanza en el trayecto del río, siendo la primera esración la que presenta los menores valores y, la lercera, la que tiene mayor concentración, clebido a las diferentes descargas que llegan a su cauce. 


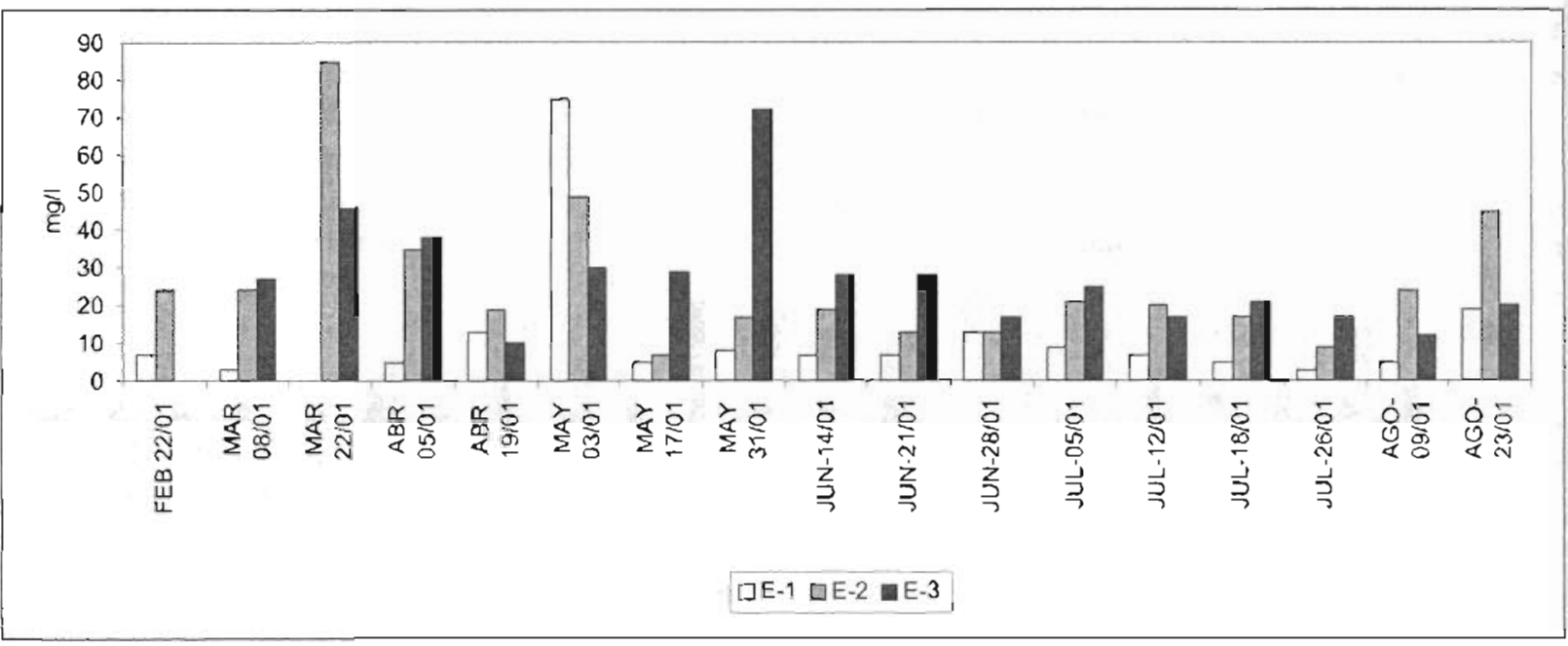

Figura 6. Voriación en la concentración de sulfatos en el período que va del 22 de febrero al 23 de agosto de 2001.

En general, los sulfatos están presentes en el río Bogotá debido al ciclo del azufre, el cual en cierta parte, llega al cauce debido al ácido sulfúrico y los sulfuros que son utilizados en el proceso de curtido de pieles y otro porcentaje es producido por la descomposición de la materia fecal.

El rango de variación para la estación uno. está comprendido entre 0 y $75 \mathrm{mg} /$, para la estación dos, entre 7 y $85 \mathrm{mg} /$ y para la estación tres. entre 10 y $72 \mathrm{mg} /$. El Decreto 1594 de 1984 en sus Artículos 38 y 39 establece como valor máximo admisible para consumo humano y doméstico uma concentración de $400 \mathrm{mg} /$ de sulfatos; $100^{\%}$ de los dacos cumplen con este rango de aceptabilidad.

\section{CONCLUSIONES}

Aparte de los resultados mencionados anteriormente, se realizó el análisis de los otros parámetros, encontrándose en general que la estación uno (E-1), por ser la más cercana del nacimiento del río y no recibir ningún tipo de descarga de tipo inclustrial y muy pocas de tipo doméstico, presentô menores valores que las otras dos estaciones en turbiedad, temperatura, demanda bioquímica de oxígeno (DBO), demanda química de oxígeno (DQO), $\mathrm{pH}$, alcalinidad, dureza, cloruros, amonio, nitritos, nitratos, fosfatos, sulfatos, cromo VI, cobre y la mayor concentración de oxigeno disuelto. Las estaciones dos y tres presentan mayor contaminación, ya que reciben gran cantidad de vertimientos provenientes de las industrias y los alcantarillados municipales, presentando así la segunda estación los mayores valores de DBO, pH, alcalinidad, amonio, fosfatos altos, fosfatos bajos, cromo VI, cobre y la terceríl estación de turbiedad, temperacura, conductividad, DQO, dureza, cloruros, nitritos, nitratos, fosfatos bajos, sulfatos, cloro libre, así como la menor concentración de oxigeno disuelto, la cual evidencia el deterioro del río, a través de su recorrido.

\section{BIBLIOGRAFÍA}

I. METCALF, Eddy. Ingenería de aguas residuales, Mc Graw Hill, 1990.

2. OROZCO JARAMILLO, Alvaro y SALAZAR ARIAS, Ȧlväro. Tratamiento biológico de las aguas residuales. Medéllin: CESET, may. $1987.155 p$.

3. MINA MARULANDA, Nacianceno. Colidad del agua. 1989. 79p. (Universidad Distrital Francisco José de Caldas).

4. Nuevos inérodos de rratamiento de ağua / Departamento de ingeniería y ciencias del ambiente. Cencro panamericano de ingenieril silmitaria CEPIS. 1973,476 p.

5. ARBOLEDA VALENCIA. Jorge, y SINGL.EY PHD. J. Edward. Teoría y prictica de la purificación del agua. Florida: AWWA. reb. 1992.480p. 